\title{
Spatiotemporal integration in somatosensory perception: effects of sensory saltation on pointing at perceived positions on the body surface
}

\author{
Jörg Trojan ${ }^{1 *}$, Annette M. Stolle ${ }^{1 \dagger}$, Antonija Mršic Carl ${ }^{1+}$, Dieter Kleinböhl ${ }^{1}$, Hong Z. Tan ${ }^{2}$ and Rupert Hölzl ${ }^{1}$ \\ 1 Otto Selz Institute for Applied Psychology, University of Mannheim, Mannheim, Germany \\ 2 School of Electrical and Computer Engineering, Purdue University, West Lafayette, IN, USA
}

\section{Edited by:}

Frans Verstraten, Utrecht University, Netherlands

Reviewed by:

Chris Dijkerman, Utrecht University, Netherlands

Rob Van Beers, Vrije Universiteit

Amsterdam, Netherlands

*Correspondence:

Jörg Trojan, Otto Selz Institute for Applied Psychology, University of Mannheim, 68131 Mannheim, Germany.

e-mail:joerg.trojan@osi.uni-mannheim. de

\section{${ }^{+}$Present address:}

Annette M. Stolle, The BG Trauma Center, Ludwigshafen, Germany. Antonija Mršić Carl, User Interface Design GmbH, Mannheim Germany.
In the past, sensory saltation phenomena (Geldard and Sherrick, 1972) have been used repeatedly to analyze the spatiotemporal integration capacity of somatosensory and other sensory mechanisms by means of their psychophysical characteristic. The core phenomenon consists in a systematic mislocalization of one tactile stimulus (the attractee) toward another successive tactile stimulus (the attractant) presented at another location, increasing with shorter intervals. In a series of four experiments, sensory saltation characteristics were studied at the forearm and the abdomen. Participants reported the perceived positions of attractees, attractants, and reference stimuli by pointing. In general, saltation characteristics compared well to those reported in previous studies, but we were able to gain several new insights regarding this phenomenon: (a) the attractee-attractant interval did not exclusively affect the perceived attractee position, but also the perceived attractant position; (b) saltation characteristics were very similar at different body sites and orientations, but did show differences suggesting anisotropy (direction-dependency) in the underlying integration processes; (c) sensory saltation could be elicited with stimulation patterns crossing the body midline on the abdomen. In addition to the saltation-specific results, our experiments demonstrate that pointing reports of perceived positions on the body surface generally show pronounced systematic biases compared to veridical positions, moderate intraindividual consistency, and a high degree of inter-individual variability. Finally, we address methodological and terminological controversies concerning the sensory saltation paradigm and discuss its possible neurophysiological basis.

Keywords: illusion, somatosensory perception, spatiotemporal integration

\section{INTRODUCTION}

\section{THE SENSORY SALTATION PHENOMENON}

Cutaneous perception relies on spatial and temporal integration mechanisms, which are limited to particular stimulation characteristics. Stimulation patterns not meeting these specifications may give rise to illusions and other paradoxical perceptions. Sensory saltation is one of these illusions, consisting of systematic distortions in the spatial perception of spatiotemporal stimulus patterns: if two stimuli are presented at two different positions with a short delay, the perceived position of the first stimulus is mislocalized toward the position of the second stimulus and this mislocalization increases with decreasing delays between the two stimuli. This phenomenon was first systematically evaluated by Frank A. Geldard and colleagues, originally introduced as cutaneous rabbit effect (Geldard and Sherrick, 1972); but Geldard later proposed sensory saltation as a more formal term (Geldard, 1975).

Saltation is not restricted to the tactile domain, but has also been demonstrated for cutaneous heat-pain stimuli (Trojan et al., 2006), auditory (Bremer et al., 1977; Hari, 1995; Shore et al., 1998; Phillips and Hall, 2001; Boehnke and Phillips, 2005; Getzmann, 2009) and visual spatial perception (Lockhead et al., 1980) as well as auditory pitch perception (Getzmann, 2007). These findings suggest that sal- tation at the perceptual level reflects general spatiotemporal processing features of the sensory system. In line with an earlier suggestion by Geldard and Sherrick (1983), Wiemer et al. (2000) argued that the saltation phenomenon may be the perceptual correlate of the dynamic behavior of sensory maps in the brain, more specifically, the primary somatosensory cortex. This assumption is supported by neurobiological studies, which demonstrate that the topography of activations found in the primary somatosensory cortex is a function of the spatial and temporal input statistics (Clark et al., 1988; Braun et al., 2000). In addition, a recent neuroimaging study demonstrated that activation in the primary somatosensory cortex indeed related to the perceived "illusionary" position of saltatory stimuli (Blankenburg et al., 2006). It is conceivable that phenomena like the tau illusion (Helson and King, 1931; Lechelt and Borchert, 1977) or the ventriloquist effect (e.g., Alais and Burr, 2004; SotoFaraco et al., 2004) may have similar neurophysiological bases.

A number of different, sometimes quite complex stimulus patterns were used in the classic studies at Geldard's lab. However, the psychophysical characteristics of the core phenomenon are demonstrated best in the so-called utterly reduced rabbit and reduced rabbit patterns. In the utterly reduced rabbit pattern, only two stimuli are presented; the first stimulus is termed attractee and the second is 
termed attractant, referring to their expected roles of being attracted vs. attracting, respectively (Geldard, 1975). In the reduced rabbit pattern, an additional reference stimulus is presented well before the attractee at the same position. While the two stimuli of the utterly reduced rabbit pattern are sufficient to demonstrate the phenomenon, the three stimuli reduced rabbit pattern additionally allows to determine the actual amount of attractee mislocalization by comparing it to the reference position'.

Most of our knowledge on sensory saltation dates back to the landmark work of Geldard and co-workers at the Cutaneous Communication Laboratory at Princeton, in particular, Carl Sherrick and Roger W. Cholewiak ${ }^{2}$. With the exception of Cholewiak's continued work (Cholewiak, 1976, 1999; Cholewiak and Collins, 2000), research into this phenomenon has risen again just recently and fostered additional observations (see Flach and Haggard, 2006, for a comprehensive review of the earlier literature). On the one hand, the core of the saltation effect was confirmed: the perceived distance between two close stimuli presented in fast succession decreases with decreasing inter-stimulus intervals. On the other hand, many aspects were qualified. Two particular findings are of special importance for our own studies:

1. With a symmetrical variation of the reduced rabbit pattern, Kilgard and Merzenich (1995) demonstrated that the roles of attractee and attractant can be switched between the two stimuli by explicitly directing the participant's attention to the designated attractant. Their conclusion that saltation is the result of "symmetric convergence," with the perceived directional shifts only introduced by cognitive biases, has been challenged by more recent results (including our own, see below). Nonetheless, it became evident that the distinction between attractee and attractant is not as clear-cut as suggested by Geldard, and that mutual interactions between them have to be considered.

2. More recently, Eimer et al. (2005) showed that an attractant presented on one arm can influence an attractee presented on the other. On the one hand, this result is in conflict with Geldard and Sherrick's (1983) assumption that somatosensory saltation results from dynamic shifts within the primary somatosensory cortex of one hemisphere and therefore should not yield effects across the body midline. On the other hand, the protocol used by Eimer et al. requires participants to integrate stimuli from anatomically separate limbs and thus to refer to a three-dimensional representation of the body and peripersonal space (cf., Holmes and Spence, 2004). This is clearly different from Geldard's (1982, 1985) original task, which focused on a two-dimensional somatotopic representation of the body surface.

'In this paper Geldard's original terms "attractee" and "attractant" are used for the sake of comprehensibility. Note, however, that there are some caveats to these descriptors: on the one hand, they only express the expected roles of these stimuli in the context of the saltation phenomenon. Whether the attractee is indeed attracted by the attractant in a given trial is an empirical question. On the other hand, they should not be understood to exclude contrariwise effects altogether. Although not addressed by the original studies, perceptual shifts of the attractant itself toward the attractee may also be present, but their detection depends on the participant's task and/or response mode (see below).

${ }^{2}$ Note that numerous studies were never published as journal articles but are only available as reports of the Princeton Cutaneous Research Project. See http://www. tactileresearch.org for a complete listing.

\section{AIMS}

In Geldard's original setup, the "illusionary" position of the attractee was not indicated directly; rather, its mislocalization was judged in terms of fractions of the absolute distance between reference and attractant. Recent studies strove for explicit localization ratings, e.g., by assessing forced-choice decisions on whether the attractee was perceived at a given position or not (Eimer et al., 2005), or by asking participants to choose one of several predefined positions on a depiction of the arm (Flach and Haggard, 2006).

Our main aim was to evaluate the saltation phenomenon in terms of direct localization ratings. Participants were instructed to point at perceived positions on their body surface with a $3 \mathrm{D}$ tracker device. The recorded responses indicate the individual perceptual representations of the stimuli as back-projections to the body surface. These back-projected perceived positions are then referenced to the grid of actual stimulus positions, yielding measures of their absolute deviation from the corresponding physical stimulus coordinates.

A second aim concerned the question of how saltation characteristics are connected to specific topographic features of the stimulation site. Saltation has rarely been studied at body sites other than the upper extremities (Geldard, 1982, 1985; Cholewiak, 1999; Cholewiak and Collins, 2000). So, in addition to the "classic" forearm area, we decided to assess saltation characteristics on the abdomen. There, we intended to examine the (an-)isotropy - that is direction-dependency - of saltation characteristics by comparing stimulus patterns applied in different directions relative to the body axis.

In addition, we wanted to shed more light on the issue of somatosensory saltation crossing the body midline. On the ventral thorax, Geldard $(1982,1985)$ had observed that attractee displacements ceased as soon as the attractant was presented more than about one centimeter beyond the body midline. We intended to reassess this finding with bilateral stimulus patterns on the abdomen.

\section{EXPERIMENTS 1 AND 2}

Using a wide range of attractee-attractant delays, we expected to replicate the essential feature of the saltation phenomenon, i.e., to demonstrate a negative relationship between attractee-attractant delay and the amount of attractee mislocalization toward the attractant.

The direct localization task also allowed us to explore deviations of the perceived reference and attractant positions. While the original saltation paradigm does not consider effects on these stimuli, we were interested in whether these positions are indeed perceived in an unbiased manner.

Last but not least, unlike many earlier studies on saltation, we explicitly reduced possible visual anchors by preventing participants from seeing the stimulators. This was achieved by either applying the stimuli to the volar forearm from below (experiment 1 ) or by shielding the stimulators from view (experiment 2).

\section{MATERIAL AND METHODS \\ Participants}

In experiment 1, fifteen healthy participants (six male; $25.5 \pm 7.4$ years) took part. All but one female were right-handed according to the Edinburgh Handedness Inventory (Oldfield, 1971). 
In experiment 2 , another 18 healthy participants ( 14 male; $25 \pm 4.9$ years) took part. One subject was left-handed and one ambidextrous. All participants were informed according to the declaration of Helsinki and gave written consent. The study designs were approved by the local ethics committee.

\section{Apparatus}

Pneumatically driven tactile stimulus arrays were used to stimulate the left volar forearm (experiment 1 ) and theleft dorsal forearm (experiment 2). Both displays consisted of a linear array of eight tactile stimulators, evenly spaced at distances of $15 \mathrm{~mm}$ between each other, covering a total distance of $105 \mathrm{~mm}$. Each stimulator consisted of a $1 \mathrm{~mm}$-diameter piston rod exerting a maximum force of $2.4 \mathrm{~N}$ (rising slope: $2.4 \mathrm{~N} / 3.5 \mathrm{~ms}$; falling slope: $<0.5 \mathrm{~N} / 6.5 \mathrm{~ms})$. Stimulus patterns were controlled by a custom-made computer program (Zappe et al., 2004).

The participants' left arms were immobilized by bedding them in a concave armrest and were visible throughout the experiment. In experiment 1 , stimuli were applied to the ventral forearm from below through the bottom of the armrest, thus blocking the view of the stimulators; in experiment 2, stimuli were applied from above to the dorsal forearm (Figure 1), and the stimulators were hidden by a screen. Both displays were positioned with the first stimulator $80 \mathrm{~mm}$ proximal to the wrist. The sound produced by the tactile stimulators was masked by white noise presented through headphones.

In both experiments, participants indicated the perceived position of each stimulus by pointing at it with their right hand using the tip of a 3D tracker system (ISOTRAK II, Polhemus 3Space; sampling rate: $60 \mathrm{~Hz}$; static accuracy: $2.4 \mathrm{~mm}$ (RMS) in all directions; spatial resolution: $0.04 \mathrm{~mm}$ ).

\section{Experimental design}

The experimental protocol was the same for both experiments 1 and 2. Three different types of stimulus patterns were applied: a single location pattern, saltation pattern A (corresponding to the reduced rabbit in Geldard's original terms), and saltation pattern B (corresponding to Geldard's utterly reduced rabbit).

The single location pattern consisted of one stimulus only per trial. Single stimuli were applied at eight different positions on the forearm (Figure 1). This pattern was used to assess point

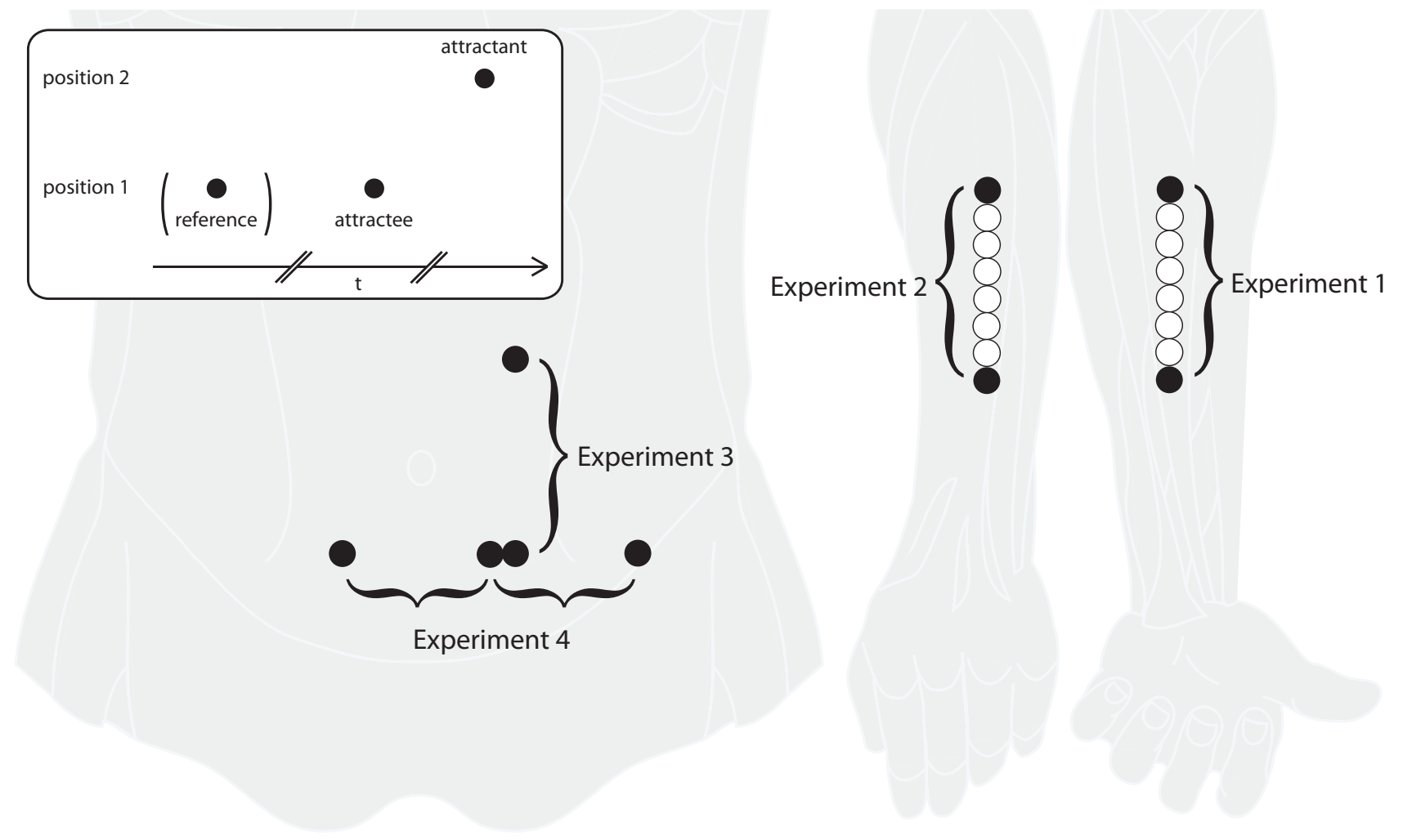

FIGURE 1 | Experimental paradigm and stimulation areas. The inset in the upper left shows a typical sensory saltation trial, consisting of a reference (missing in the "utterly reduced rabbit" pattern), an attractee, and an attractant. Reference and attractee are always presented at the same position with a constant SOA of about 1000 ms. The attractant is presented at a different position with a variable delay. Experiments 1 and 2 were performed at the ventral and dorsal forearm, respectively, with reference and attractee always being presented at the most distal position and the attractant being presented at the most proximal position. In experiment 3, saltation patterns were presented at the left abdomen in vertical direction, both upward and downward. In experiment 4, saltation patterns were presented in horizontal direction on the abdomen, either unilaterally or bilaterally, always from left to right. In addition to the saltation patterns, single stimuli at a total of eight positions (those used in the saltation trials and six in between), were presented in experiments 1 and 2 . See the Method sections for details on positioning and spacing of the stimulus positions. 
localization without the influence of spatiotemporal integration. One block consisted of eight trials with stimulus positions in pseudo-randomized order (sequence: stimulator 3, 8, $2,5,1,6,4,7)$. A total of six blocks was applied during the experimental session.

Saltation pattern A ("reduced rabbit") consisted of three stimuli (reference, attractee, attractant) sequentially applied at a spatial distance of $105 \mathrm{~mm}$. Reference and attractee were always presented at the most distal position, the attractant was always presented at the most proximal position. The constant delay between reference and attractee was $1020 \mathrm{~ms}$ (Figure 1). The delay (i.e., stimulus onset asynchrony, SOA) between attractee and attractant varied between 0 and $1020 \mathrm{~ms}$, using a total of 19 different values. All delays were presented in pseudo-randomized order within one block (sequence: 140, 20, 1020, 515, 260, 366, 240, 100, 160, 180, $80,725,60,0,200,70,40,220,120 \mathrm{~ms})$. During the session, a total of six blocks were applied.

Saltation pattern B ("utterly reduced rabbit") consisted of two stimuli (attractee, attractant) sequentially applied at a spatial distance of $105 \mathrm{~mm}$ (Figure 1): the attractee was presented with the most distal stimulator (1) and the attractant with the most proximal stimulator (8) near the elbow. As in saltation pattern A, each of the 19 delays between attractee and attractant were presented in trials of pseudo-randomized order within each block (sequence: 1020, $220,0,200,60,180,140,70,100,120,160,240,80,366,725,40$, $20,260,516 \mathrm{~ms})$. Six blocks repeating the 19 different trials were applied during the session.

The total of 18 blocks (six blocks of the single location patterns with eight trials, six blocks of saltation pattern A with 19 trials, and six blocks of saltation pattern B with 19 trials) were presented in pseudo-randomized order. Consequently, each participant received a total of 276 trials within the experimental session, lasting just below $1 \mathrm{~h}$.

\section{Reporting method}

Participants were always informed about the actual amount of stimuli they would receive in each trial, that is three in saltation pattern A, two in saltation pattern B, and one in the single location pattern. They were instructed to report all positions in the sequence they had perceived them directly after the respective pattern had been presented.

For reporting the positions, participants rested the pen-shaped tracker on the edge of the armrest such that the tip of the tracker was at the same distal-proximal level as the perceived position and confirmed this by pressing a button on the tracker. The tip of the tracker was typically held no more than $2 \mathrm{~cm}$ from the skin and participants were free to move their head to adjust their field of view, minimizing possible biases of differing visual angles.

\section{Data preprocessing}

A one-dimensional scale in proximal-distal direction was anchored to the stimulation area on the forearm. The perpendicular of the three-dimensional coordinates to this scale constituted the position information used in the analysis. The positions of wrist and elbow on this scale were used to determine individual arm length. In order to plot and analyze data from all participants in the same reference system, all data were normalized to this length.

\section{Indicators of sensory saltation}

Being the most straightforward indicator for sensory saltation, the perceived position of the attractee is expected to be displaced toward the attractant with shorter delays. However, this measure does not account for effects on the stimulation pattern as a whole, possibly affecting the attractant (or even the reference) as well. As a more robust indicator for the amount of sensory saltation, we calculated the relative attractee displacement, defined as the distance between the perceived positions of the reference and the attractee divided by the distance between the perceived positions of the reference and the attractant. Obviously this was only possible for saltation pattern A, where the perceived reference position was measured.

\section{Statistics}

Effects of the experimental factors were analyzed using linear mixed models (LMM). These have significant advantages over usual (M) ANOVA techniques, because they allow the inclusion of random effects, such as inter-individual differences in response characteristics (see West et al., 2007 for an introduction focused on its practical use). The models estimated fixed effects for attractee-attractant delay, block order, and intercept as well as random effects for block order and intercept $t^{3}$. Linear contrasts were used to check for the presence of steadily decreasing effects of the attractee-attractant delay. In regard to our hypotheses, we were interested in the (1) fixed effects of attractee-attractant delay, (2) the fixed effects of block order, and (3) the linear contrast of attractee-attractant delay. For these three effects, probabilities were corrected to account for false discovery rates using the procedure suggested by Benjamini and Hochberg (1995).

Linear mixed models were estimated with the "mixed" procedure of SPSS 17.0.2 using default options. Additional analyses and preparation of figures was performed with R 2.8 (R Development Core Team, 2009).

All calculations were performed with values normalized to individual arm lengths, measured as the distance between wrist and elbow (see Data Preprocessing). Missing data were excluded.

For the plots of group results shown in Figures 2-4, position means were first calculated within each participant for each condition; then means and SEMs of these aggregated values were calculated.

\section{RESULTS}

\section{Perceived positions of single location stimuli}

Participants were generally able to consistently differentiate between stimulus positions, reflected in the linear relation between veridical and perceived stimulus positions and the standard deviations of the position ratings (see Figure 2). However, reports of perceived stimuli were generally shifted proximally, and the range of average perceived stimulus positions appeared to be compressed compared to the range of veridical stimulus positions (reductions of about $40 \%$ in experiment 1 and $50 \%$ in experiment 2; estimated from the regression coefficients).

${ }^{3}$ Intercepts were included in the models to account for general offsets in the localization data, but they are not relevant to our hypotheses. The random effects of block order and intercept allowed for individual differences concerning the impact of fixed effects. This preferred model was derived from theoretical assumptions, and its fit was compared to those of others of higher and lower complexity on the basis of likelihood ratio tests and pragmatic considerations, following the general approach suggested by West et al. (2007). Because the results of those model selection analyses bear no consequences on our main results, they will not be reported in detail. 

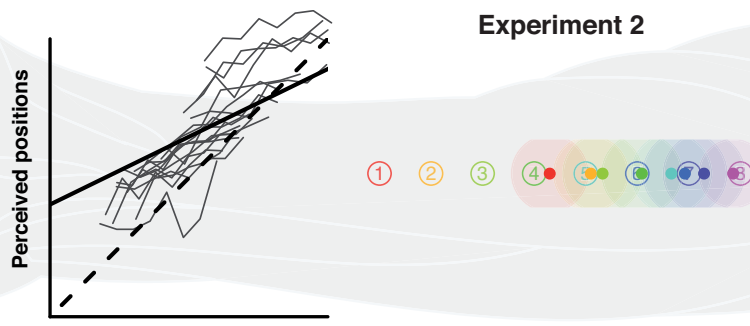

Physical positions

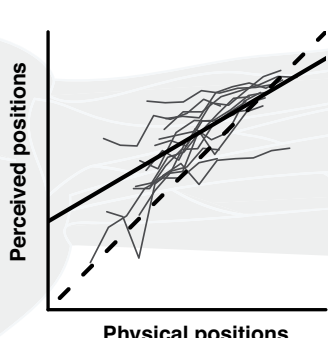

Physical positions

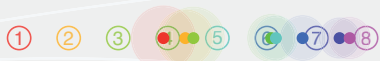

FIGURE 2 | Single stimulus localization in experiments 1 and 2. Numbered circles indicate physical stimulus positions averaged over all participants. Colored dots indicate average perceived positions, surrounded by a halo designating variability in terms of SEMs. The line graphs show the relationship between perceived and physical positions. The lengths of the axes equate to individual arm length. Thin gray lines: individual localization profiles averaged by position; black straight line: the group regression based on the averaged individual regression parameters; black dashed line: the (theoretical) gradient of absolute correspondence between the two dimensions, values above indicating proximal and values below denoting distal displacements. Individual data were processed in respect to the distal-proximal dimension of the forearm and normalized to individual arm lengths, measured as the distance between wrist and elbow (see Data Preprocessing). All positions are shown in units of this normalized armlength.

\section{Effects of attractee-attractant delay on perceived attractee displacement}

In both saltation patterns, the attractee was systematically displaced toward the attractant in the vast majority of trials (pattern A: 91\%; pattern B: 94\%). The delay between attractee and attractant had a strong effect on the amount of relative attractee displacement (pattern A) and absolute attractee position (patterns A and B) (Tables 1 and 2). The shorter the delay, the greater was the amount of attractee displacement (Figures 3 and 4). At very short attractee-attractant delays, the amount of attractee displacements appeared to be diminished in experiment 1, but not in experiment 2 (see also Figure 7).

\section{Effects of attractee-attractant delay on the perceived positions of attractant and reference}

The perceived position of the attractant was generally influenced by the attractee-attractant delay, as well (Tables 1 and 2). In both experiments, attractants were localized more distally with decreasing attractee-attractant delays in both saltation patterns, as can be seen in the positive values of the linear contrasts. However, this effect was considerably less pronounced than the attractee displacement. References were only presented in saltation pattern $\mathrm{A}$, and only in experiment 2 was a significant effect of attractee-attractant delay present for their perceived positions. The linear trend contrast indicated slightly more proximal localization with decreasing attractee-attractant delay, but, again, only a subgroup seemed to be affected at all.

\section{Effects related to time and repetition}

In all of the models used in the above analyses, fixed and random effects of block order were included to check for changes related to stimulus repetition and temporal order. In experiment 1 , the perceived reference and attractee positions of saltation pattern $A$ as well as attractee and attractant positions of saltation pattern $B$ were reported at increasingly proximal positions over the course of the experiment (Table 1). This result was due to particularly strong increases in a subgroup of participants, mainly in the first half of the trials in each block. In experiment 2 , block order affected the attractant of saltation pattern A, and, again, attractee and attractant of saltation pattern B (Table 2). Here, the subgroup of participants contributing to these effects was even smaller, and only in the attractees of saltation pattern $\mathrm{B}$ the differences between blocks formed a trend to more proximal positions.

\section{DISCUSSION \\ Saltation characteristics}

In line with former reports (Geldard and Sherrick, 1972; Geldard, 1975; Cholewiak, 1999; Flach and Haggard, 2006), the displacement of the attractee toward the attractant increased with decreasing delays between the stimuli. This result demonstrates that the perceived topology of somatosensory stimulus patterns not only depends on their spatial but also on their spatiotemporal, that is 
Table 1 | Linear mixed model solutions for the dependent variables in experiment 1.

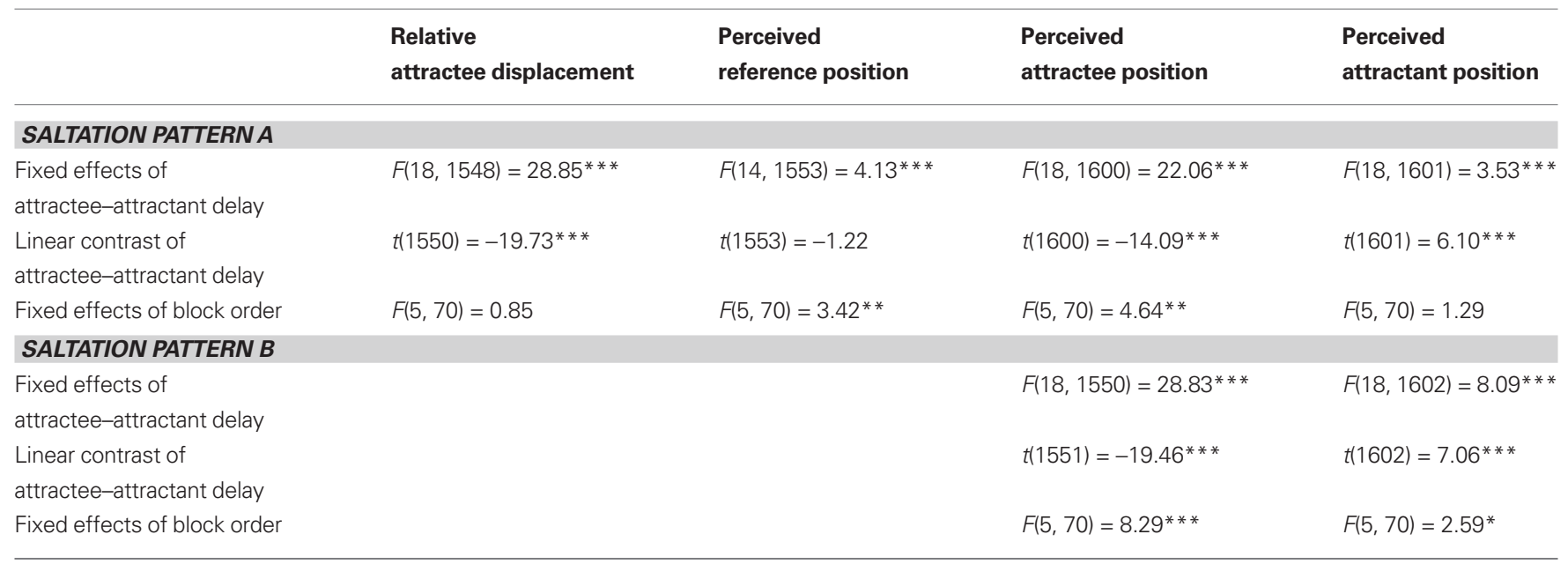

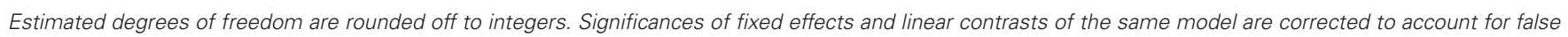

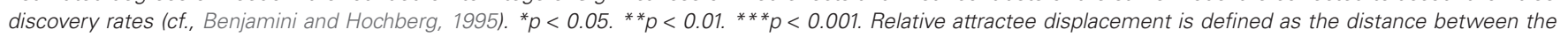
perceived positions of the reference and the attractee divided by the distance between the perceived positions of the reference and the attractant.

Table 2 | Linear mixed model solutions for the dependent variables in experiment 2.

\begin{tabular}{|c|c|c|c|c|}
\hline & $\begin{array}{l}\text { Relative } \\
\text { attractee displacement }\end{array}$ & $\begin{array}{l}\text { Perceived } \\
\text { reference position }\end{array}$ & $\begin{array}{l}\text { Perceived } \\
\text { attractee position }\end{array}$ & $\begin{array}{l}\text { Perceived } \\
\text { attractant position }\end{array}$ \\
\hline \multicolumn{5}{|l|}{ SALTATION PATTERN A } \\
\hline $\begin{array}{l}\text { Fixed effects of } \\
\text { attractee-attractant delay }\end{array}$ & $F(18,1868)=53.00^{* * *}$ & $F(18,1868)=5.99 * * *$ & $F(18,1924)=25.47^{* * *}$ & $F(18,1924)=8.16^{* * *}$ \\
\hline $\begin{array}{l}\text { Linear contrast of } \\
\text { attractee-attractant delay }\end{array}$ & $t(1869)=-29.66^{* * *}$ & $t(1868)=-3.57^{* * *}$ & $t(1924)=-15.89 * * *$ & $t(1924)=7.36^{* * *}$ \\
\hline \multicolumn{5}{|l|}{ SALTATION PATTERN B } \\
\hline $\begin{array}{l}\text { Fixed effects of } \\
\text { attractee-attractant delay }\end{array}$ & & & $F(18,1870)=62.89 * * *$ & $F(18,1926)=7.84^{* * *}$ \\
\hline $\begin{array}{l}\text { Linear contrast of } \\
\text { attractee-attractant delay }\end{array}$ & & & $t(1871)=-30.50 * * *$ & $t(1926)=9.35^{* * *}$ \\
\hline
\end{tabular}

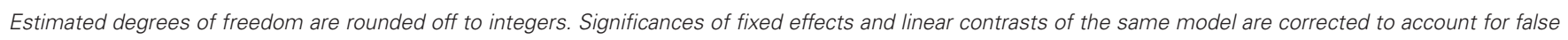

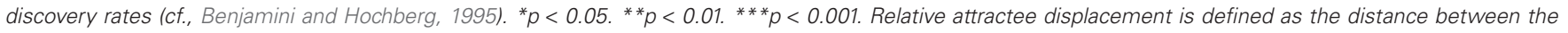
perceived positions of the reference and the attractee divided by the distance between the perceived positions of the reference and the attractant.

dynamic characteristics. Saltation could be elicited in each participant; however, the individual parameters of the observed characteristics varied to a great extent.

Notably, only minor differences were present between stimulation at the ventral (experiment 1) and the dorsal (experiment 2) forearm. The generally reduced saltation characteristics at the ventral compared to the dorsal forearm may simply reflect differences in scaling, introduced by having to point "through" the arm. At attractee-attractant delays of up to $40 \mathrm{~ms}$, the amount of attractee displacements appeared to be diminished in experiment 1 (see also Figure 7). This may be due to a decreased certainty of ratings at these very short delays: stimuli passed undetected only rarely (55 of all 1710 pattern A trials in experiment 1), but if it happened, mainly delays up to $40 \mathrm{~ms}$ were affected (39 of those 55 cases).
We demonstrated attractee displacements at all studied delays of 0 to $1020 \mathrm{~ms}$, deviating from the span of 20-320 ms originally reported by Geldard and his co-workers (Geldard and Sherrick, 1972; Geldard, 1975). Furthermore, participants in the studies of Geldard (1975) perceived coincidence of the attractee and the attractant at the physical position of the attractant at short delays. In the present study, however, coincidence was rarely observed, even at the simultaneous presentation of attractee and attractant. These discrepancies most likely reflect the differences in the methods of psychophysical scaling and were also present in experiments 3 and 4 (see below).

We did not find remarkable differences between the two saltation patterns. This is in contrast to the findings by Flach and Haggard (2006), who reported more pronounced mislocalization in their "attractee-first 3-tap" (i.e., "reduced rabbit") than in their 


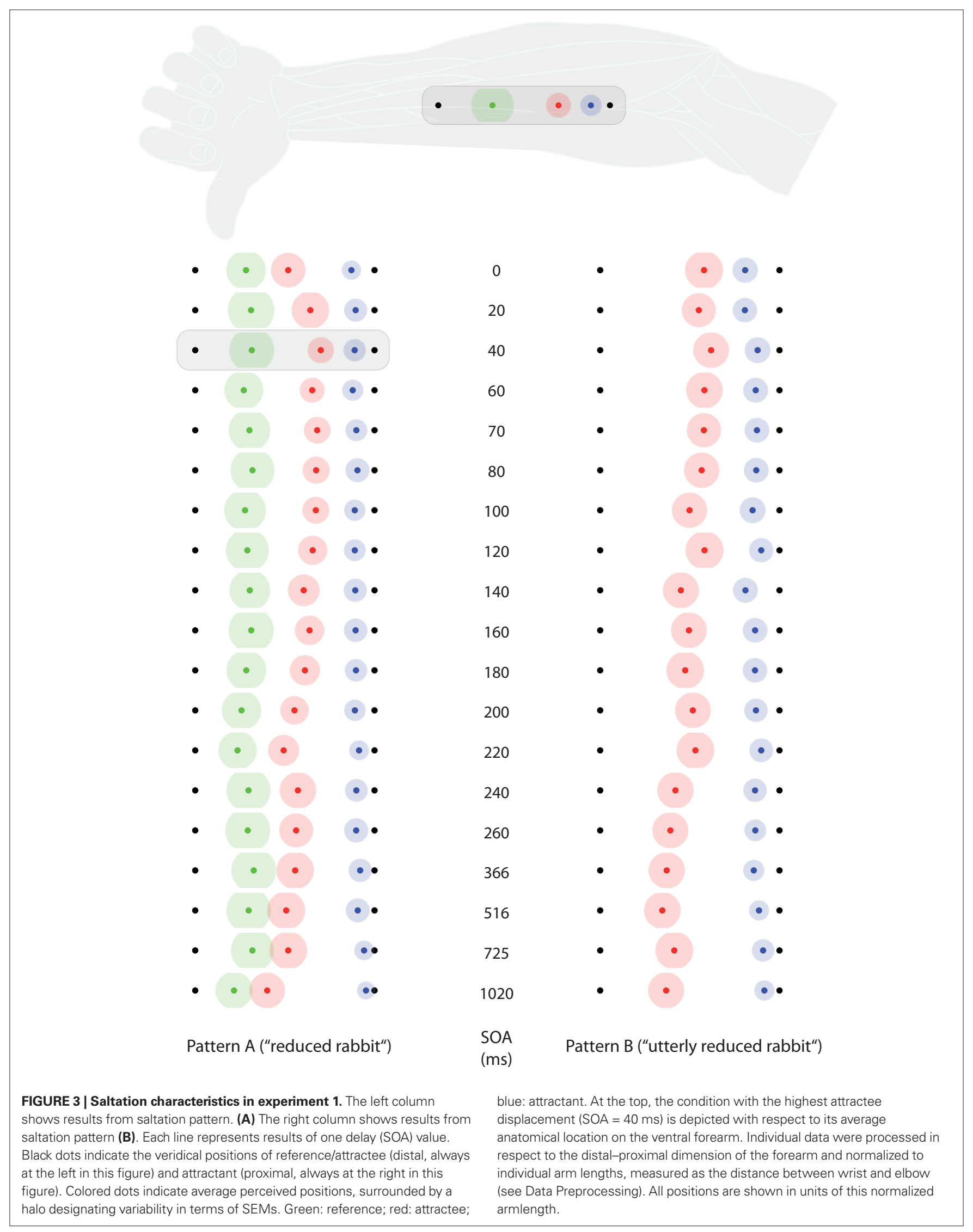




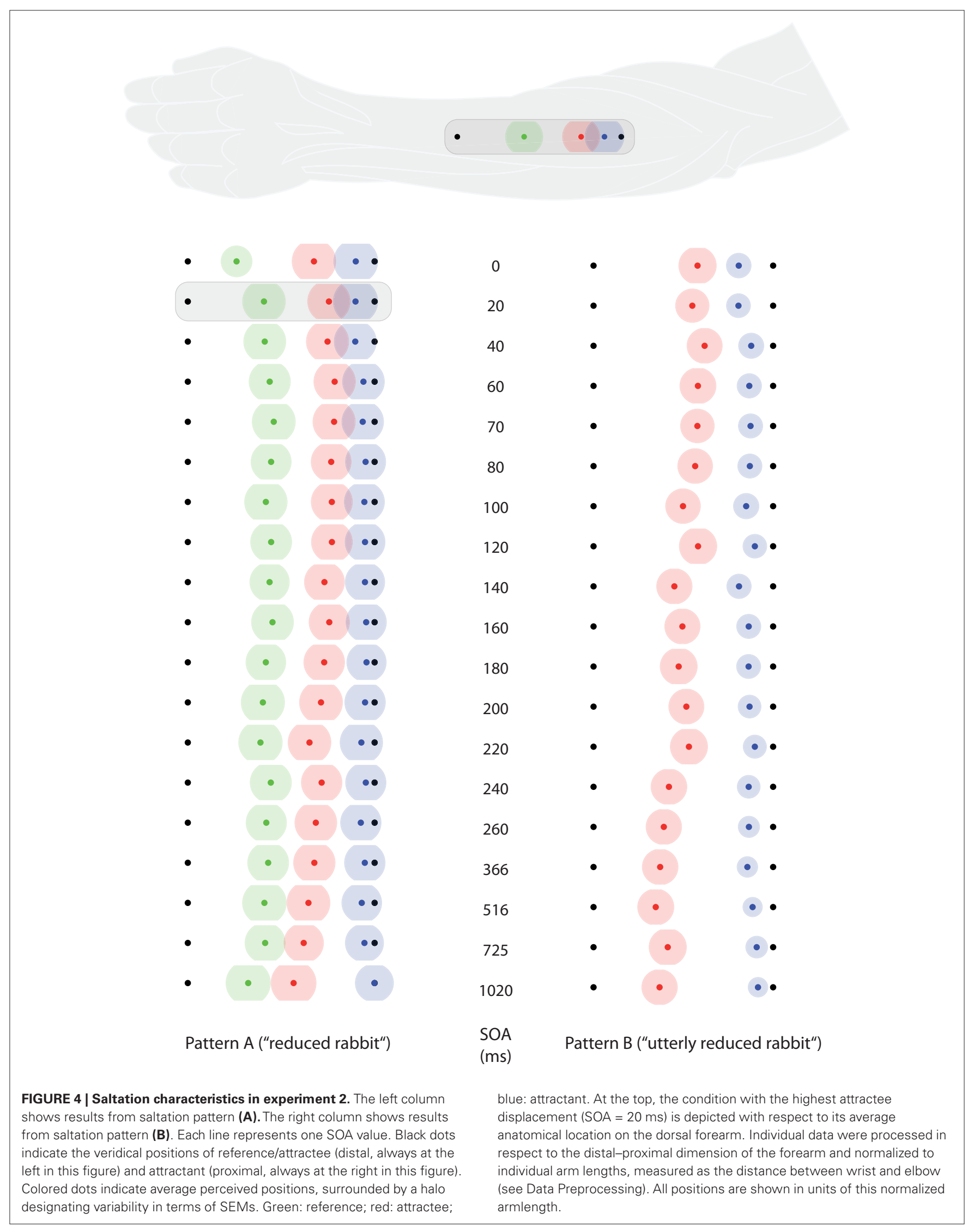


"attractee-first 2-tap" (i.e., "utterly reduced rabbit") condition. In that study, however, mislocalization was measured by having participants decide at which of eight possible positions they had perceived the attractee; separate ratings of attractant and reference positions were not performed. It seems possible that these differences in methodology are responsible for the differing results. This issue will be addressed in more detail in the Section "General Discussion."

\section{Systematic mislocalization of single stimuli, references, and attractants}

In deviation to other implementations of the saltation phenomenon, our setup allowed separate reports of the perceived reference and attractant positions. Possible mislocalization of these stimuli was never taken into account in earlier studies; they were either artificially "fixed" by instructions or reporting methods ${ }^{4}$, or they were not to be reported by the participants at all. Our results show that a more detailed look at these stimuli is essential for understanding the mechanism of sensory saltation.

First, the implicit assumption that non-saltatory stimuli, including reference and attractant, are perceived at their veridical positions is wrong. Already single stimuli were systematically mislocalized in proximal direction and compressed to about a half of their veridical range, distal stimuli being more affected than proximal stimuli (Figure 2). This effect is also present in the perceived reference and attractant positions (Figures 3 and 4), indicating that spatiotemporal integration underlying sensory saltation acts on top of an already spatially distorted map.

Second, references and attractants were dynamically affected by the attractee-attractant delay. At long attractee-attractant delays, perceived attractant positions did not differ considerably from those of single stimuli presented at the same position; at shorter delays, however, they were "drawn" toward the attractee. This means that the saltation phenomenon is not restricted to the "saltatory" attractee, but also encompasses a displacement of the attractant, although to a somewhat smaller extent. Intriguingly, in experiment 2 even the reported position of the reference in the "reduced rabbit" pattern showed a relation to the attracteeattractant delay.

Third, even if these effects are controlled for by using the relative attractee displacement as an indicator for saltation, an offset in the perceived attractee position persists at attracteeattractant delays of up to one second, which is clearly beyond the specifications originally reported by Geldard. We assume that this offset is not part of saltation "proper" but rather represents an additional effect, possibly relating to the fact that the reference stimulus was not visually anchored to a specific position as in Geldard's studies.

The observations that delay-dependent displacements are not limited to the attractee but extend to the whole stimulus pattern - albeit differentially - bear important implications on our understanding of the saltation phenomenon. They will be addressed in the light of the results of all experiments in the Section "General Discussion."

${ }^{4}$ In most studies of the Geldard group, participants had to rate the amount of saltation in relation to the reference and attractant positions, which were visually anchored by the stimulators attached there.

\section{Effects of time and/or repetition}

The observed variations related to block order are minor in most participants. Only in some of them, clear trends in distal or proximal direction could be observed, the latter being more common. Changes occurring within the first half of the experimental sequence seem to be responsible for the largest part of the effect, resembling some kind of "self-calibration" or "tuning in." One can only speculate which processing level (or which combination of levels) may be responsible for this effect; possibilities range from basic perceptual learning over altered cognitive criteria to improved pointing skills.

\section{EXPERIMENTS 3 AND 4}

Elaborating on the results of the preceding experiments, we implemented a setup for the application of saltation stimuli to the abdomen. In experiment 3 , saltation patterns were presented unilaterally in vertical orientation, either in upward or in downward direction. In experiment 4 , the same stimulus patterns were presented in horizontal orientation, unilaterally as well as bilaterally, to examine whether saltation can be elicited by patterns crossing the body midline.

\section{METHOD}

\section{Participants}

Twenty-nine healthy volunteers ( 12 males) participated in experiment 3 , and all but four of them also took part in experiment 4 . The sample was drawn from Purdue University students $(N=22$; age $18-26$ years) and laboratory staff ( $N=7$; age $18-32$ years). Non-staff participants were recruited by written advertisement and were paid on an hourly basis for their participation. All participants signed an informed consent statement. The study was pre-approved by the local ethics committee and was performed in accordance with the Declaration of Helsinki.

\section{Apparatus}

Stimuli were applied with vibrating tactors (Audiological Engineering Corp.) of $2.5 \mathrm{~cm}$ diameter, driven at a fixed frequency of $284 \mathrm{~Hz}$ by an audio amplifier (based on LM380, National Semiconductor Corp.). Stimulus duration and delays (i.e., stimulus onset asynchronies) were controlled by a micro-controller (ATMEL AT902313-10PC, Atmel Corp.) and appropriate computer programs. All tactors were attached to the inner side of a belt made of stretchable thick felting, which was strapped around the lower torso and covered the abdomen. No cues on where the tactors were placed were visible on the surface of the belt.

In experiment 3 , the stimuli were applied in a vertical arrangement to the left side of the participants' abdomen. The lower active tactor was placed at the level of the anterior superior iliac spines and the upper active tactor was placed $7 \mathrm{~cm}$ away from it in vertical direction toward the costal arch. Their horizontal position equaled $33 \%$ of the distance between the anterior superior iliac spines at each side of the body (Figure 5). In experiment 4, tactors were placed at three positions between the anterior superior iliac spines, from left to right at (a) 12.5\%, "lateral left," (b) $37.5 \%$, "medial left" and (c) 62.5\%, "medial right" (mean distance: $6.75 \mathrm{~cm}$; SD $1.05 \mathrm{~cm}$ ) (Figure 6). In both experiments, two additional dummy tactors were placed in between the two active tactors to prevent participants from guessing where exactly stimulation was to occur. 

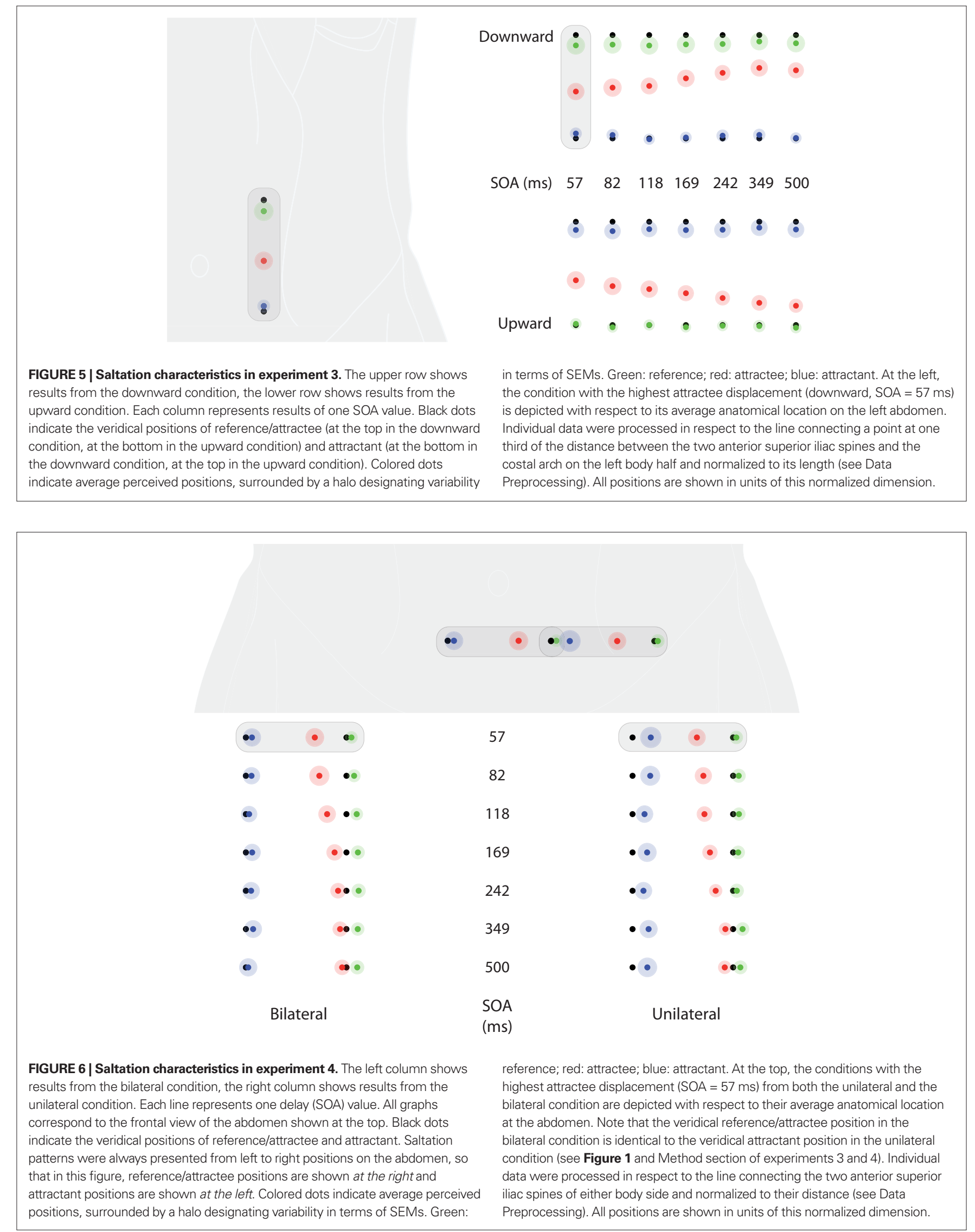
Participants were seated in an office chair in a comfortable, leaned-back position. A 3D tracker system (FASTRAK II, Polhemus 3Space; sampling rate: $120 \mathrm{~Hz}$; static accuracy: $0.8 \mathrm{~mm}$ (RMS) in all directions; spatial resolution: $0.005 \mathrm{~mm}$ ) was used to measure the perceived positions as indicated by the participants.

\section{Experimental design}

"Reduced rabbit" sequences were used as saltation patterns, consisting of three successive vibratory stimuli of $40 \mathrm{~ms}$ duration. The first stimulus served as a reference, followed by a second "saltatory" attractee at the same site after a constant delay of $700 \mathrm{~ms}$. The third stimulus, the attractant, was applied to a second site. The delay between attractee and attractant varied in the range of 57-500 ms in seven steps: 57, 82, 118, 169, 242, 349, and $500 \mathrm{~ms}$.

In experiment 3 , the sequence of stimuli in relation to the longitudinal body axis was varied: in presentation mode "upward," reference and attractee were applied with the lower position, placed at the line connecting the anterior superior iliac spines, and the attractant was applied at the upper position, placed $7 \mathrm{~cm}$ away from it in vertical direction toward the costal arch; in the "downward" condition, reference and attractee were presented at the upper position and the attractant was presented at the lower position (Figure 1).

In experiment 4, we used two other presentation modes: in condition "unilateral," reference and attractee were applied at the lateral left position and the attractant at the medial left position, so that both stimuli were applied to the same side of the body; in condition "bilateral," reference and attractee were applied at the medial left position and the attractant was applied at the medial right position, causing the stimulus pattern to cross the body midline (Figure 1).

In both experiments, one full set of trials consisted in combinations of each of the seven delay values with both presentation modes ("upward" vs. "downward" and "unilateral" vs. "bilateral," respectively) in pseudo-randomized order. Within the experimental session, this set was repeated six times, resulting in a total of $7 \times 2 \times 6=84$ trials. The participants' task was to indicate the site of the perceived positions with the $3 \mathrm{D}$ tracker.

As in experiments 1 and 2, the relative attractee displacement (the distance between the perceived positions of the reference and the attractee divided by the distance between the perceived positions of the reference and the attractant) was used as an indicator for sensory saltation.

\section{Reporting method}

Participants were informed that they would receive three stimuli in each trial. They were instructed to report all positions in the sequence they had perceived them directly after the respective pattern had been presented.

Participants were asked to hold the tip of the tracker above the area in which they had felt the stimulus, without touching the belt, and to confirm the positions by pressing a button on the tracker. The tip of the tracker was held close to the surface of the belt and participants were free to move their head to adjust their field of view, minimizing possible biases of differing visual angles.

\section{Data preprocessing}

In experiment 3, a one-dimensional scale in rostral-caudal direction was anchored to the lower stimulus position on the line connecting the anterior superior iliac spines and the lower end of the costal arch vertical to this position. In experiment 4 , a one-dimensional scale in horizontal direction was anchored to the left and right anterior superior iliac spine. The perpendicular of the three-dimensional coordinates to these scales constituted the position information used in the analysis. In order to plot and analyze data from all participants in the same reference system, all data were normalized to these lengths.

Anatomical reference positions (anterior superior iliac spines, intersection of left lateral line, and costal arch) were measured, as well, to allow normalizing.

\section{Statistics}

As in experiments 1 and 2, analyses were performed using LMM. For experiment 3, relative attractee displacement was predicted with fixed effects of attractee-attractant delay, direction, block order, intercept, and the interaction of attractee-attractant delay and direction. For experiment 4 , relative attractee displacement was predicted with fixed effects of attractee-attractant delay, laterality, block order, intercept, and the interaction of attractee-attractant delay and laterality. In both cases, random effects for block order and intercept were included. The perceived positions of reference, attractee, and attractant referred to different veridical positions in upward, downward, unilateral, and bilateral conditions; thus, for these dependent variables, separate analyses were performed within condition. These analyses included fixed effects of attracteeattractant delay, block order, and intercept as well as random effects of block order and intercept. In regard to our hypotheses, we were interested in (1) the fixed effects of direction (experiment 3 ) and laterality (experiment 4), (2) the fixed effects of attractee-attractant delay, and (3) the fixed effects of block order. For these effects, probabilities were corrected to account for false discovery rates using the procedure suggested by Benjamini and Hochberg (1995).

Linear mixed models were estimated with the "mixed" procedure of SPSS 17.0.2 using default options. Additional analyses and preparation of figures was performed with R 2.8 (R Development Core Team, 2009).

All calculations were performed with values normalized to individual body proportions, i.e., the distance between the levels of the anterior superior iliac spines and the costal arch (experiment 3) or the distance between the anterior superior iliac spines of either body side (experiment 4). Missing data were excluded.

For the plots of group results shown in Figures 5 and 6, position means were first calculated within each participant for each condition; then means and SEMs of these aggregated values were calculated.

\section{RESULTS}

\section{General accordance of physical and perceived positions}

In experiment 3, a general small downward shift affected the ratings of the upper stimuli both in the downward condition (references) and in the upward condition (attractants). The perceived positions of the upper and lower stimuli did not differ between conditions; and in neither condition did the perceived positions of the reference and attractant stimuli averaged per participant differ significantly 
from the actual physical positions of the stimuli (Wilcoxon signed rank tests, both n.s.). In experiment 4 , most stimuli were rated as being perceived more leftwards than their veridical positions, but, when averaged per participant, a trend could be observed only for the references (Wilcoxon signed rank tests, both $p<0.10$ ). The stimulus presented at the medial left position was perceived more medially in the bilateral condition, when it served as a reference, than in the unilateral condition, when it served as an attractant (Figure 6; green: reference; blue: attractant). In addition, an interaction between laterality and attractee-attractant delay was observed, also reflecting its differing role in the two conditions (cf. results for unilateral and bilateral presentation modes, below). In the bilateral presentation mode, reports of attractees being perceived at positions across the body midline were rare (15\% of all trials, present in
15 out of 25 participants). However, most of these ratings coincided with a relative attractee displacement larger than 50\% (9\% of all trials, present in 14 out of 25 participants), suggesting that they do reflect genuine "hops" across the midline.

\section{Effects of attractee-attractant delay on perceived attractee displacement}

As expected, the perceived position of the attractee was systematically displaced toward the attractant depending on attracteeattractant delay, indicating the occurrence of sensory saltation (Figures 5 and 6). This result is reflected in a strong main effect of the attractee-attractant delay on the amount of relative attractee displacement (Tables 3 and 4): the shorter the delay, the greater was the amount of displacement.

\section{Table 3 | Linear mixed model solutions for the dependent variables in experiment 3.}

\section{Relative attractee displacement}

Fixed effects of attractee-attractant delay

$F(6,2249)=61.11 * * *$

Fixed effects of direction

$F(1,2249)=31.49 * * *$

Interaction between attractee-attractant delay and direction

$F(6,2249)=0.58$

Fixed effects of block order

$F(5,140)=2.16^{*}$

\section{Perceived reference position}

\section{DIRECTION UP}

Fixed effects of attractee-attractant delay

Fixed effects of block order

\section{DIRECTION DOWN}

Fixed effects of attractee-attractant delay

Fixed effects of block order

\author{
$F(6,1038)=2.08$ \\ $F(5,140)=1.10$
}

$F(6,1038)=31.64^{* * *}$

$F(5,140)=1.90$
$F(6,1038)=0.98$

$F(5,140)=0.89$
$F(6,1038)=2.06$
$F(6,1038)=34.73^{* * *}$
$F(6,1038)=3.90 * * *$
$F(5,140)=0.52$
$F(5,140)=1.93$
$F(5,140)=1.38$

Estimated degrees of freedom are rounded off to integers. Significances of fixed effects and linear contrasts of the same model are corrected to account for false discovery rates (cf., Benjamini and Hochberg, 1995). ${ }^{*} p<0.05 .{ }^{* *} p<0.01 .{ }^{* *} p<0.001$. Relative attractee displacement is defined as the distance between the perceived positions of the reference and the attractee divided by the distance between the perceived positions of the reference and the attractant.

Table 4 | Linear mixed model solutions for the dependent variables in experiment 4.

\begin{tabular}{|c|c|c|c|c|}
\hline \multicolumn{5}{|c|}{ Relative attractee displacement } \\
\hline \multicolumn{2}{|l|}{ Fixed effects of attractee-attractant delay } & \multicolumn{3}{|c|}{$F(6,1781)=75.98^{* * *}$} \\
\hline \multicolumn{2}{|l|}{ Fixed effects of laterality } & \multicolumn{2}{|c|}{$F(1,1781)=31.72^{* * *}$} & \\
\hline \multicolumn{2}{|c|}{ Interaction between attractee-attractant delay and laterality } & \multicolumn{2}{|c|}{$F(6,1781)=2.50^{*}$} & \\
\hline \multirow[t]{2}{*}{ Fixed effects of block order } & & \multicolumn{2}{|c|}{$F(5,110)=2.57^{*}$} & \\
\hline & Perceive & rence position & Perceived attractee position & Perceived attractant position \\
\hline \multicolumn{5}{|l|}{ UNILATERAL } \\
\hline Fixed effects of attractee-attractant delay & \multicolumn{2}{|c|}{$F(6,822)=3.56^{*}$} & $F(6,822)=31.13^{* * *}$ & $F(6,822)=1.85$ \\
\hline Fixed effects of block order & \multicolumn{2}{|c|}{$F(5,140)=0.54$} & $F(5,140)=1.94$ & $F(5,140)=1.02$ \\
\hline \multicolumn{5}{|l|}{ BILATERAL } \\
\hline Fixed effects of attractee-attractant delay & \multicolumn{2}{|c|}{$F(6,822)=3.56^{* *}$} & $F(6,822)=29.43 * * *$ & $F(6,822)=1.06$ \\
\hline Fixed effects of block order & \multicolumn{2}{|c|}{$F(5,140)=0.42$} & $F(5,140)=1.74$ & $F(5,140)=1.22$ \\
\hline
\end{tabular}

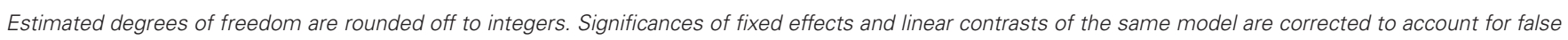

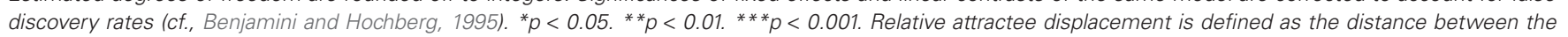
perceived positions of the reference and the attractee divided by the distance between the perceived positions of the reference and the attractant. 
Effects of direction and laterality on perceived attractee displacement Presentation in upward direction consistently led to smaller amounts of relative attractee displacement than in downward direction, without any interaction with attractee-attractant displacement (Table 3). Averaged across participants, the saltation characteristics looked very similar, basically only differing in their intercept (Figures $\mathbf{5}$ and 7). Unilateral presentation yielded higher relative displacements than bilateral presentation at constant absolute distances between the stimulus positions, and an interaction with attractee-attractant delay was present (Table 4), reflecting the saltation characteristics being flatter in the bilateral condition (Figures 6 and 7).

\section{Effects on the perceived positions of attractant and reference}

In experiment 3, neither for references nor for attractants did we observe any displacement systematically related to the attracteeattractant delay; only in the statistical analysis of the "down" condition, attractee-attractant delay yielded a significant effect on attractant localization (Table 3 ). However, visual inspection of the data showed that this latter effect does not result from a systematic relation, but rather from exceptionally high unsystematic variations in a subgroup of participants. In experiment 4 , significant effects of attractee-attractant delay were present for the localization of the reference (Table 4), and in this case the results may indeed reflect minor systematic relations. In any case, all of these effects are considerably smaller than those on the attractee and thus only account for a fragment of the relative attractee displacement chosen as indicator for the saltation phenomenon.

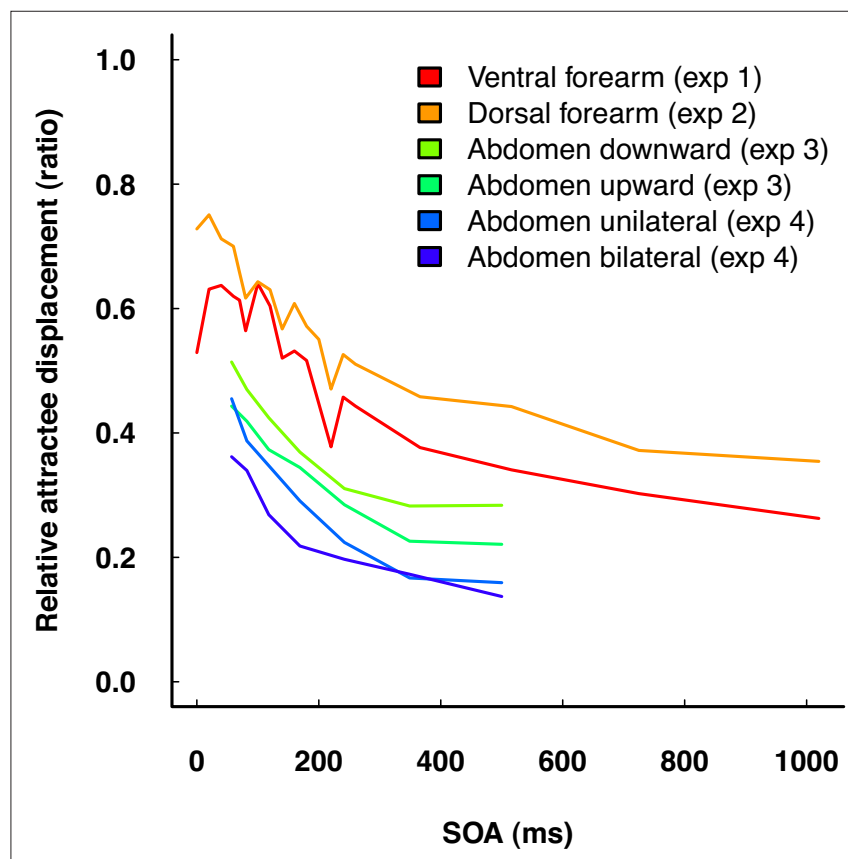

FIGURE 7 | Summary of relative attractee displacement by delay (SOA) in "reduced rabbit" patterns from all four experiments. Note that the amount of attractee displacement is not readily comparable across experiments, due to differences in physical stimulus characteristics as well as to potentially different cortical magnification factors of the body sites. Nonetheless, the gradient of the characteristics is very similar across experiments.

\section{Effects of time course}

In neither of the experiments could any systematic influence of time course be observed on the group level. Repeated blocks did yield significant effects on relative attractee displacement in the statistical analysis across both directions in experiment 3 (Table 3) as well as across laterality conditions in experiment 4 (Table 4), but these effects were rather associated with unsystematic variations across blocks. When analyzed by direction, no temporal effect whatsoever was present in the perceived location parameters (Tables 3 and 4).

\section{DISCUSSION}

Experiments 3 and 4 investigated saltation on the abdomen, with a special focus on spatial anisotropy, i.e., differences of saltation characteristics depending on the direction of the stimulus pattern (upward vs. downward presentation) or its extension across body regions (unilateral vs. bilateral presentation). As expected, the relative displacement of the attractee systematically depended on attractee-attractant delay under all conditions in both experiments. The shorter the delay, the greater the amount of attractee displacement was. The observed characteristics generally compare well to the results of experiments 1 and 2. The two most important findings were that (a) saltation characteristics systematically depended on the orientation of the presented patterns, and that (b) saltation could be shown across the body midline, challenging Geldard's original assumptions on the cortical mechanisms involved.

\section{Longitudinal anisotropy}

Saltation was slightly, but consistently, more pronounced in the downward compared to the upward direction, which means that the two direction conditions differ in terms of a constant offset in the relative attractee displacement. The perceived positions of upper and lower stimuli did not differ between conditions, i.e., they were not affected by whether they served as references in one direction or as attractants in the other. The fact that the amount of attractee displacement - reflecting spatiotemporal processing - was specifically affected by direction, while reference and attractant positions were not, is an indicator for anisotropy.

\section{Saltation across the body midline}

Saltation could be elicited with stimulus patterns crossing the body midline, demonstrating integrative processing of bilaterally applied stimuli. The saltation characteristics in the unilateral condition were different from those in the bilateral condition, showing marginally more attractee displacement, especially at the shortest delay. However, these differences are in the same order of magnitude as those between the upward and downward condition in experiment 3 and those between the ventral and dorsal forearm in experiments 1 and 2, calling a specific role of crossing the body midline into question. Some participants even sporadically perceived attractees on the other side of the body midline, contralateral to the veridical position, although, admittedly, these cases were rare. Complementing the report by Eimer et al. (2005), this finding shows that not only can attractants on one body half influence attractees on the other; at least in principle, attractees can even be "drawn" across the body midline. 
Geldard and Sherrick (1983) had hypothesized that saltation results from spatiotemporal integration in the primary somatosensory cortex of one hemisphere. Present-day knowledge on somatosensory processing puts this idea into perspective. There is increasing evidence that the secondary somatosensory cortex plays an important role in the spatiotemporal integration of information within and across body halves, and that sensory input is processed simultaneously in primary and secondary somatosensory cortex (e.g., Karhu and Tesche, 1999). Taken together, these findings suggest that the mechanisms needed for saltation to come about are rather to be found in the secondary somatosensory cortex, and that effects in the primary somatosensory cortex (Blankenburg et al., 2006) may merely represent their outcome (see General Discussion on the neurophysiological basis of saltation).

In conclusion, our finding that saltation can be elicited at all with attractee-attractant pairs crossing the body midline is not overly surprising in the light of current neurophysiological knowledge. The identification of parameters and boundary conditions, however, will be a main concern for future studies.

\section{GENERAL DISCUSSION \\ SUMMARY OF MAIN RESULTS}

Sensory saltation could be demonstrated at several sites on the body surface. The saltation characteristics found in all four experiments match those reported in the literature well. Additional insights include: (a) attractee-attractant delay does not exclusively affect the attractee position, it rather potentially affects both attractee and attractant position; (b) saltation characteristics are very similar in different body sites and orientations, but do show differences suggesting directional anisotropy in the underlying integration processes; (c) sensory saltation can be elicited with bilateral stimulation patterns on the abdomen, even including attractee displacements crossing the body midline. In addition to the saltation-specific results, our experiments demonstrate that reports of perceived positions on the body surface show pronounced systematic biases compared to veridical positions.

\section{HOPPING RABBITS AND SPATIOTEMPORAL INTEGRATION: WHAT IS THE FUNCTIONAL CORE OF SENSORY SALTATION?}

From the first reports by Geldard's group to the present day, the views on sensory saltation have undergone many changes. Still, there is confusion on how to define the core phenomenon. Some researchers mainly refer to the "multiple rabbit" pattern presented in Geldard and Sherrick's landmark article (Geldard and Sherrick, 1972) while others focus on the minimalist "utterly reduced rabbit" using only two stimulus locations. There is also no agreement on how to term the phenomenon. While Geldard - emphasizing the (supposedly) underlying principle - suggested the term "sensory saltation" (Geldard, 1975), many researchers still use the descriptive term (Flach and Haggard, 2006).

We suggest reserving the term "sensory saltation" for the fundamental phenomenon of the perceived location of a stimulus being shifted toward that of a second stimulus following closely in time (within several tens to hundreds of milliseconds). Typically, the size of this shift increases when the time interval between the stimuli decreases. This inverse relation between shift and delay might be used as a more specific defining feature of sensory saltation.
Saltation, in this descriptive sense, combined with its inverse temporal gradient, may reflect a functional principle of sensory processing, probably to be found regularly in everyday perception and not necessarily coupled to a specific experimental setup. At least, this would be indicated by the variety of stimulation patterns capable of eliciting the effect, including "reduced," "utterly reduced," "asymmetric," and "multiple rabbit" patterns. None of these patterns, however, not even the minimalist "utterly reduced rabbit," should be identified with the functional principle of sensory saltation: while all of them trigger saltation, these patterns may not necessarily be specific to saltation, but may induce other spatiotemporal integration processes in addition.

Recently, Goldreich (2007) reviewed several studies demonstrating that the application of brief stimuli in direct succession to separate positions on the skin generally leads us to underestimate the distance between these positions. As a consequence, we must assume that additional non-saltatory spatiotemporal effects contribute to the observed "saltation" results, their relative amount depending on the particular paradigm, instruction, and reporting task. In line with Goldreich's view, we observed massive attractee displacements well beyond the conventional saltatory delay range of up to $500 \mathrm{~ms}$ (Figure 6).

\section{MUTUAL ATTRACTION: THE ROLES OF REFERENCES AND ATTRACTANTS}

The issue of where reference and attractant are perceived in "reduced rabbit" and "utterly reduced rabbit" patterns has been left unconsidered in most studies. As demonstrated in our experiments, however, the perceived positions of attractants and references may be related to attractee-attractant delay, as well. As a consequence, measures of the perceived attractee position alone are ambiguous indicators of the saltatory shift.

Kilgard and Merzenich's (1995) well-known study illustrates this problem. They added a fourth stimulus to the reduced rabbit pattern to yield a temporally and spatially symmetric stimulus sequence: a first pair of stimuli (reference 1, attractee) was presented with a long, fixed interval at one position; after a short, variable delay, another pair (attractant, reference 2) was presented at a different position with the same long interval as the first pair. In this setup, the attractant was not perceived at the same position as reference 2. Rather, attractee and attractant were both perceived between references 1 and 2, their perceived separation relating to the variable short delay between them. However, when the participant's attention was explicitly directed toward reference 1 or 2 , both attractee and attractant were shifted in the indicated direction.

Kilgard and Merzenich's conclusion that saltation can be explained solely by "symmetric convergence" and anticipation seems premature because their experiment disfavored the observation of direction-specific spatiotemporal effects in somatosensory representations by putting particular stress on visual attention, thus drowning somatosensory saltation in visual bias. However, their results demonstrate clearly that the distinction between attractee and attractant is not as clear-cut as Geldard had thought.

It remains an open question, at which level of processing the effects on references and attractants presented in our data were introduced. On the one hand, it is likely that they are in part due to cognitive biases during reporting; on the other hand, causes at more fundamental levels of sensory processing cannot be excluded 
altogether. In any case, measuring the perceived positions of all stimuli will be obligatory for achieving a better understanding of the underlying processes.

\section{DETECTING, CHOOSING, SECTIONING, AND POINTING: WHICH INFORMATION IS EXTRACTED THROUGH WHICH TASK?}

Given a clear definition of sensory saltation has been agreed on, another aspect of its operationalization, that is, the kind of reporting method has to be considered when interpreting results and comparing saltation characteristics across experiments. Over the years, a variety of reporting methods has been used, which can be grouped under four headings.

The most simple reporting method is to ask the subject whether a saltatory stimulus has been perceived at a predefined position or not (e.g., Eimer et al., 2005; Blankenburg et al., 2006). In general, this two-alternative forced-choice method is not suitable to determine the quantitative relation between displacement and attractee-attractant delay, thus, it is not appropriate for demonstrating saltation in the narrower sense defined above. This does not generally preclude its use, but puts severe restriction on the interpretation of the data: if the delay-dependent characteristic cannot be demonstrated, an observed displacement can in principle result from a number of other factors, which cannot be disentangled from the saltatory effect proper.

This disadvantage is partially overcome by multiple-choice procedures giving participants the opportunity to choose between several positions in reporting where they felt the stimulus (Flach and Haggard, 2006). In principle, this allows the calculation of saltation characteristics. However, because participants are forced to integrate over predefined locations within a limited area, the sensitivity depends very much on the relationship between the number of choices, the distance covered by the stimulus array, and the expected displacements.

Geldard and his group frequently used the sectioning method (Geldard, 1975): participants either verbally reported the amount of attractee displacement as a proportion of the distance between the anchored reference and attractant positions, or they actively manipulated the attractee-attractant delay to achieve a predefined amount of displacement. This approach produces clear-cut results, but the rating requires judgments on a higher cognitive integration level (the comparison of three positions).

In our studies, direct localization through pointing was used. Pointing is the natural way of indicating positions on the body surface, especially, of tactile sensations, and pointing has a high face-validity with regard to generalization to everyday perception and behavior.

In all of the above approaches, the effect of sensory saltation is not captured in real-time but rather deduced from reports given several seconds after the presentation. However, spatial judgments are affected by the time delay between presentation and report, probably due to relying on two different types of representations, depending on how much time has passed (Rossetti, 1998). Rapid behavioral responses are determined by implicit, egocentric, representations, usually termed body schema; later responses rely more on cognitive evaluation and depend on explicit, allocentric representations, often referred to as body image (cf. Gallagher, 2005). Pointing appears to be closer to the body schema than the methods used in previous studies. However, our participants could take all the time they needed to report the perceived positions and such slow pointing movements are influenced by the body image, as well (Kammers et al., 2009).

Delays are expected to reduce spatial accuracy in egocentric representations, but they may improve spatial accuracy in allocentric representations (Zuidhoek et al., 2003). Systematically varying response delays in future studies can disentangle the relative share of these two levels in eliciting the saltation phenomenon and will help approximating its functional core.

In the light of these methodological discrepancies it is surprising how well results of different studies do compare after all. This points to the functional unity of the core phenomenon and indicates the relevance of the underlying mechanisms of sensory saltation for understanding the role of spatiotemporal integration in everyday perception, in particular, its role in somatosensory representations of the body surface and their interaction with other modalities. For this purpose, however, a more unified methodological framework is needed for future research.

\section{HOMUNCULI AND MULTI-DIMENSIONAL SENSORY MAPS: NEUROPHYSIOLOGICAL BASES OF SALTATION}

Geldard and others originally thought that sensory saltation resulted from spatiotemporal integration in the primary somatosensory cortex (SI) (Geldard and Sherrick, 1983; Wiemer et al., 2000), but this view has been put into perspective by newer findings.

First, our results show that attractants presented on one side of the body influence attractees on the other side of the body. Such midline-crossing effects would not be possible if the underlying processes were restricted to one hemisphere.

Second, the phenomenon is not restricted to two-dimensional representations of the body surface as provided by SI. Eimer et al. (2005) demonstrated that attractants presented on one arm influenced attractees on the other arm. Integrating across anatomically separate limbs, however, requires three-dimensional representations of these limbs and their position in external space, provided by visual and/or proprioceptive information. Displacement of somatosensory attractees is not even restricted to the body surface. Miyazaki et al. (2010) let participants press both of their index fingers to the lower side of a stick mounted in horizontal direction in front of them. Then they applied a "reduced rabbit" pattern to the upper side of the stick, with reference and attractee at the position of one finger and the attractant at the position of the other finger. Participants typically felt reference and attractant close to the veridical positions while the attractee was perceived at a position in-between.

Third, sensory saltation is not limited to the somatosensory domain, but it has been in observed in many other sensory modalities. Intriguingly, even cross-modal effects can be demonstrated, as in our own recent demonstration of tactile-auditory saltation (Trojan et al., 2009).

The above examples show that a convincing explanation of sensory saltation cannot be based on representations in SI alone. The secondary somatosensory cortex (SII) has been reported to be involved in spatiotemporal integration of somatosensory stimuli (Zhu et al., 2007) and it receives information from both body halves (Disbrow et al., 2001). This suggests that SII may be involved in 
unimodal somatosensory saltation, but it is also clear that neither SI nor SII mechanisms can explain cross-modal saltation or perceptions on external objects. This points to further levels of integration in frontal and parietal areas, related to body image, body schema, and peripersonal space (Holmes and Spence, 2004).

\section{ACKNOWLEDGMENTS}

This study was supported by a focal research program grant of the state Baden-Württemberg "Berechnung und Transformation visueller Merkmale für taktile Sehersatzsysteme" ("Computation and transformation of visual features for tactile sensory substitution systems"), the DFG Grant Ho 904/10-12 as part of the Clinical Research Group "Learning and Plasticity in Chronic Pain" (KFO107), and the Sixth Framework Program of the European Union, project no. 043432, "SOMAPS.” Jörg Trojan is indebted to the Baden-Württemberg Foundation for the financial support of this research project by the elite program for postdocs. We thank Thomas Scheller, Alfred Kube, and Stefan Keiz (Mannheim) as well as John W. Leimgruber (Purdue) for their technical support and their help in setting up the experiments. Thorsten Maucher and Karlheinz Meier (University of Heidelberg) kindly provided the prototype of the pneumatic stimulation setup used in experiments 1 and 2 , including the control software, which was adapted to our

\section{REFERENCES}

Alais, D., and Burr, D. (2004). The ventriloquist effect results from nearoptimal bimodal integration. Curr. Biol. 14, 257-262.

Benjamini, Y., and Hochberg, Y. (1995). Controlling the false discovery rate: a practical and powerful approach to multiple testing. J. R. Stat. Soc. Series B 57, 289-300.

Blankenburg, F., Ruff, C. C., Deichmann, R., Rees, G., and Driver, J. (2006). The cutaneous rabbit illusion affects human primary sensory cortex somatotopically. PLoS Biol. 4, e69. doi: 10.1371/journal.pbio.0040069.

Boehnke, S. E., and Phillips, D. P. (2005). Auditory saltation in the vertical midsagittal plane. Perception 34, 371-377.

Braun, C., Wilms, A., Schweizer, R., Godde, B., Preissl, H., and Birbaumer, N. (2000). Activity patterns of human somatosensory cortex adapt dynamically to stimulus properties. Neuroreport 11, 2977-2980.

Bremer,C.D., Pittenger,J.B., Warren, R., and Jenkins, J. J. (1977). An illusion of auditory saltation similar to the cutaneous “rabbit”. Am. J. Psychol. 90, 645-654.

Cholewiak, R. W. (1976). Satiation in cutaneous saltation. Sens. Processes 1, 163-175.

Cholewiak, R. W. (1999). The perception of tactile distance: influences of body site, space, and time. Perception 28, 851-875.

Cholewiak, R.W., and Collins, A.A. (2000). The generation of vibrotactile patterns

needs by Jens Keuchel. Further thanks go to Andreas Möltner and Brady T. West for statistical advice. Last but not least, we sincerely thank Roger W. Cholewiak for his long-standing support, providing access to the archives of the Princeton Cutaneous Communication $\mathrm{Lab}$, and comments on earlier versions of the manuscript.

\section{AUTHOR CONTRIBUTIONS}

Annette M. Stolle carried out, analyzed, and drafted reports on experiments 1 and 2, which were part of her PhD project. She supervised experiments 3 and 4, and contributed substantially to the theoretical background. Antonija Mršić Carl carried out, analyzed, and drafted reports on experiments 3 and 4 in the course of her Psychology diploma project. Jörg Trojan re-analyzed the data from all experiments, prepared figures, and, based on the existing reports, wrote the article. Hong Z. Tan supervised the experiments carried out at Purdue University ( 3 and 4). Dieter Kleinböhl contributed to the conceptual framework and theoretical background, supervised the experiments carried out at the University of Mannheim, and was involved in the experimental setups and data analyses. Rupert Hölzl initiated the research program on saltation as a model paradigm for spatiotemporal integration from which the reported studies have been derived, supervised the experiments carried out at the University of Mannheim, and coedited the final paper.

its presumed neural basis. Percept. Psychophys. 33, 299-304.

Getzmann, S. (2007). Saltation in pitch perception. Exp. Brain Res. 179 , 571-581.

Getzmann, S. (2009). Exploring auditory saltation using the "reducedrabbit" paradigm. J. Exp. Psychol. Hum. Percept. Perform. 35, 289-304.

Goldreich, D. (2007). A bayesian perceptual model replicates the cutaneous rabbit and other tactile spatiotemporal illusions. PLoS One 2: e333. doi: 10.1371/journal.pone.0000333.

Hari, R. (1995). Illusory directional hearing in humans. Neurosci. Lett. 189, 29-30.

Helson, H., and King, S. M. (1931). The tau effect: an example of psychological relativity. J. Exp. Psychol. 14, 202-217.

Holmes, N. P., and Spence, C. (2004). The body schema and the multisensory representation(s) of peripersonal space. Cogn. Process. 5, 94-105.

Kammers, M. P., de Vignemont, F., Verhagen, L., and Dijkerman, H. C. (2009). The rubber hand illusion in action. Neuropsychologia 47 , 204-211.

Karhu, J., and Tesche, C. D. (1999). Simultaneous early processing of sensory input in human primary (SI) and secondary (SII) somatosensory cortices. J. Neurophysiol. 81, 2017-2025.

Kilgard, M. P., and Merzenich, M. M. (1995). Anticipated stimuli across skin. Nature 373, 663.
Lechelt, E. C., and Borchert, R. (1977). The interdependence of time and space in somesthesis: the tau effect reexamined. Bull. Psychon. Soc. 10, 191-192.

Lockhead, G. R., Johnson, R. C., and Gold, F. M. (1980). Saltation through the blind spot. Percept. Psychophys. 27, 545-549.

Miyazaki, M., Hirashima, M., and Nozaki, D. (2010). The "cutaneous rabbit" hopping out of the body. J. Neurosci. 30, 1856-1860.

Oldfield, R.C. (1971). The assessment and analysis of handedness: the Edinburgh inventory. Neuropsychologia 9, 97-113.

Phillips, D. P., and Hall, S. E. (2001). Spatial and temporal factors in auditory saltation. J. Acoust. Soc. Am. 110(Pt 1), 1539-1547.

R Development Core Team. (2009). $R$ : A Language and Environment for Statistical Computing. Vienna: $\mathrm{R}$ Foundation for Statistical Computing.

Rossetti, Y. (1998). Implicit short-lived motor representations of space in brain damaged and healthy subjects. Conscious. Cogn. 7, 520-558.

Shore, D. I., Hall, S. E., and Klein, R. M. (1998). Auditory saltation: a new measure for an old illusion. J. Acoust. Soc. Am. 103, 3730-3733.

Soto-Faraco, S., Spence, C., and Kingstone, A. (2004). Cross-modal dynamic capture: congruency effects in the perception of motion across sensory modalities. J. Exp. Psychol. Hum. Percept. Perform. 30, 330-345. 
Trojan, J., Getzmann, S., Möller, J., Kleinböhl, D., and Hölzl, R. (2009). Tactile-auditory saltation: spatiotemporal integration across sensory modalities. Neurosci. Lett. 460, 156-160.

Trojan, J., Stolle, A. M., Kleinböhl, D., Mørch, C. D., Arendt-Nielsen, L., and Hölzl, R. (2006). The saltation illusion demonstrates integrative processing of spatiotemporal information in thermoceptive and nociceptive networks. Exp. Brain Res. 170, 88-96.

West, B., Welch, K. B., and Galecki, A. T. (2007). Linear Mixed Models: A Practical Guide Using Statistical Software. Boca Raton: Chapman \& Hall/CRC.
Wiemer, J., Spengler, F., Joublin, F., Stagge, P., and Wacquant, S. (2000). Learning cortical topography from spatiotemporal stimuli. Biol. Cybern. 82, 173-187.

Zappe, A. C., Maucher, T., Meier, K., and Scheiber,C. (2004). Evaluation of a pneumatically driven tactile stimulator device for vision substitution during $\mathrm{AMRI}$ studies. Magn. Reson. Med. 51, 828-834.

Zhu, Z., Disbrow, E. A., Zumer, J. M., McGonigle, D. J., and Nagarajan, S. S. (2007). Spatiotemporal integration of tactile information in human somatosensory cortex. BMC Neurosci. 8, 21.

Zuidhoek, S., Kappers, A. M., van der Lubbe, R. H., and Postma, A. (2003).
Delay improves performance on a haptic spatial matching task. Exp. Brain Res. 149, 320-330.

Conflict of Interest Statement: The authors declare that the research was conducted in the absence of any commercial or financial relationships that could be construed as a potential conflict of interest.

Received: 13 July 2010; paper pending published: 28 July 2010; accepted: 01 November 2010; published online: 13 December 2010.

Citation: Trojan J, Stolle AM, Mršić Carl A, Kleinböhl D, Tan HZ and Hölzl R (2010)
Spatiotemporal integration in somatosensory perception: effects of sensory saltation on pointing at perceived positions on the body surface. Front. Psychology 1:206. doi:10.3389/fpsyg.2010.00206

This article was submitted to Frontiers in Perception Science, a specialty of Frontiers in Psychology.

Copyright (c) 2010 Trojan, Stolle, Mršić Carl, Kleinböhl, Tan and Hölzl. This is an open-access article subject to an exclusive license agreement between the authors and the Frontiers Research Foundation, which permits unrestricted use, distribution, and reproduction in any medium, provided the original authors and source are credited. 